Recepción: 20 / 04 / 2017

Aceptación: 20 / 05 / 2017

Publicación: 15 / 06 / 2017

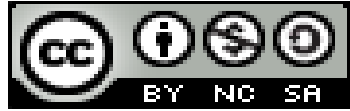

Ciencias Económicas y Empresariales

\title{
Modelo cuantitativo de riesgos laborales para el sector de la construcción en el Ecuador
}

\author{
Quantitative labor risk model for the construction \\ sector in Ecuador
}

\section{Modelo quantitativo dos riscos profissionais do sector da construção no Equador}

Miguel A. Ordoñez-Torres ${ }^{\mathrm{I}}$ miguel_ordonez77@yahoo.es

Edin A. Garcés-Coca II edin.garcesc@ug.edu.ec

Héctor D. Martínez-Villacrés III hector.martinezvi@ug.edu.ec

Correspondencia: miguel_ordonez77@yahoo.es

\begin{abstract}
I. Ingeniero Industrial; Magister en Seguridad Higiene Industrial y Salud Ocupacional, Universidad Estatal de Guayaquil, Guayaquil, Ecuador.

II. Ingeniero Aeronáutico; Especialidad "Navegación Aérea y Control de Tránsito Aéreo, Magister en Ciencias de Ingeniería, Universidad Estatal de Guayaquil, Guayaquil, Ecuador.

III. Ingeniero en Sistemas; Magister en Docencia Matemática, Universidad Estatal de Guayaquil, Guayaquil, Ecuador.
\end{abstract}




\section{Resumen}

El presente trabajo de investigación se enfoca en dar una perspectiva de la situación de la seguridad y salud laboral del sector de la construcción en el Ecuador, mediante la exploración de estudios, informes de investigación, entre otros que se hayan realizado a nivel nacional, analizando el impacto del sector en la economía del país, condiciones laborales que se mantiene en la ejecución de sus actividades, los riesgos presente en cada una de las etapas constructivas, leyes y reglamentos vigente e instituciones que regulan la seguridad y Salud laboral del sector.

Se analizan datos estadísticos de la evolución de los accidentes laborales en la última década, enfatizando en el sector de la construcción y haciendo comparación con los accidentes laborales de otros sectores económicos como son la de servicios, agrícola e Industrial, determinado la incidencia y severidad de los accidentes. A partir del conocimiento de estado actual del sector de construcción en lo referente a seguridad y salud laboral, se plantea la estructura del modelador estimativo de costes, basado en métodos cuantitativos propuesto por diferentes organismos y técnicos en la prevención riesgos laborales, se define los tipos de costos que incurren las empresas constructoras en los riesgos existente en una obra de construcción como son: "Costos Asegurado y No Asegurado". Se desarrolla un modelo de valoración cuantitativa de los riesgos laborales más comunes presente en la ejecución de una obra de construcción en el Ecuador, herramienta de resultados económica del el impacto que genera la inversión en la prevención de riesgos y que permite al empresario argumentos para la toma de decisiones.

Palabras claves: Seguridad, Salud, Laboral, Construcción, Costos, Higiene, Industrial, Ocupacional, Riesgos, Accidentes, Reglamento. 


\begin{abstract}
The present research focuses on giving an overview of the security and health situation of the construction sector in Ecuador, through scanning studies, research reports, among others that have been made at national level, analyzing the sector's impact on the economy, work conditions maintained in the performance of their activities, the risks presented in each of the construction phases, the current laws and regulations and institutions governing occupational health and safety sector. Statistical data on the evolution of labor accidents have been analyzed in the last decade, with emphasis on the construction sector and by comparison with accidents in other economic sectors such as the services of agriculture and industry, given by the incidence and severity of accidents. From the knowledge of the current state of the construction sector in terms of occupational health and safety, the structure of the estimated cost modeling is based on quantitative methods proposed by different agencies and technicians in occupational risk prevention, types costs incurred are defined by construction companies in the existing risks in a construction such as: "Costs Insured and Uninsured". A model of quantitative assessment of the most common occupational hazards present at the execution of a construction place in Ecuador, the tool of economic results of the impact that generate investment in the risk prevention and allows the employer makes some arguments for decision making.
\end{abstract}

Key words: Safety, Health, Labor, Construction, Costs, Hygiene, Industrial, Occupational, Risks, Accidents, Regulation. 


\section{Resumo}

Esta pesquisa se concentra em dar uma visão geral da situação de segurança e saúde do sector da construção, no Equador, por estudos de exploração, relatórios de pesquisa, entre outros que têm sido feitas a nível nacional, analisando o impacto do setor na economia, as condições de trabalho mantida na execução de suas atividades, os riscos presentes em cada uma das fases de construção, as leis atuais e regulamentos e instituições que regem a saúde e segurança no setor.

dados estatísticos sobre a evolução dos acidentes de trabalho são analisadas na última década, enfatizando sector da construção e por comparação com acidentes de trabalho em outros setores da economia, tais como serviços, agrícolas e industriais, determinou a incidência e gravidade de acidentes. A partir do conhecimento do estado actual do sector da construção em termos de saúde e segurança no trabalho, a estrutura dos custos modelador estimados, com base em métodos quantitativos propostos por diferentes agências e técnicos em prevenção de riscos laborais, surge tipos definidos custos incorridos por empresas de construção nos riscos existentes em um canteiro de obras, tais como: "os custos segurados e não segurados". um modelo de avaliação quantitativa dos riscos ocupacionais mais comuns presentes na execução de um canteiro de obras no Equador, os resultados económicos de ferramentas do impacto que o investimento em prevenção de riscos e que habilita os argumentos do empregador é desenvolvido para tomada de decisão.

Palavras-chave: Segurança, Saúde, Trabalho, Construção, Custos, Higiene, Industrial, riscos ocupacionais, acidentes, regulamento. 


\section{Introducción.}

El sector de la construcción en el Ecuador constituyendo un pilar importante en el desarrollo y sostenimiento de la economía, siendo un motor dinamizador de inversión y generadora de puestos de trabajos.

En los últimos años el sector ha tenido un crecimiento vertiginoso y gran parte se debe a la inversión pública, sin embargo la construcción es el sector que destaca por la numerosa cantidad accidentes laborales y los altos índices de fatalidades, debido principalmente las series de características específicas del sector tales como la complejidad e informalidad de sus procesos constructivos, la falta de planeación de las actividades, poca capacidad administrativa, alta rotación de trabajadores en las diferentes etapas de la construcción, interacción de numerosas empresas en el mismo centro de trabajo, desarrollo de las actividades constructivas a la intemperie, la continua movilidad de los puestos de trabajo y la incipiente formación de los obreros y técnicos en materia de seguridad y salud laboral.

El Ecuador actualmente cuenta con un Reglamento de Seguridad y Salud de Trabajadores y Mejoramiento del Medio Ambiente aprobado en 1986, bajo decreto ejecutivo 2393, el Reglamento de Seguridad y Salud para la Construcción de Obras Públicas aprobado en el 2008 bajo acuerdo ministerial 0174 , normativas que se crearon para exigir a las industrias la implementación de planes y programas de prevención en los centros de trabajos, así mejorar los ambientes de laborales y la

Problemática de la accidentabilidad laboral en el país. Con la vigencia de los reglamentos antes descritos no ha existido un cambio significativo en la prevención de riesgos laborales en especial en el sector de la construcción, lo que nos hace llegar a la conclusión que para lograr cambios en la prevención de los riesgos laborales, a más de nuevas leyes, es necesario un cambio de 
concepción de los empresarios, gerentes y todos los mandos jerárquico que lideran el sector de la construcción, que el significado de la prevención es igual a rentabilidad y se conceda mayor importancia a la necesidad de gestionar prevención antes los riesgo presentes en una obra de construcción.

El factor más ponderarte de los accidentes laborales, sea quizás el importe económico que incurre el país. De acuerdo con estimaciones de Organización Internacional del Trabajo (OIT) los costos económicos son aproximadamente un $4 \%$ del producto interno bruto (PIB) global anual. En el Ecuador la pérdida económica equivale entre el $8 \%$ y $10 \%$ del PIB.

Las estadísticas generales de accidentes laborales que se registran en el Ecuador según la OIT, “el 98\% de los casos son sub-registros, no solo señalando las debilidades en cuanto a la falta de prevención de accidentes y enfermedades laborales en las empresas. Sitúan a Ecuador a la cabeza en Siniestralidad laboral oculta en América Latina, produciéndose 2 registros de cada 100 accidentes ocurridos reflejando el estado de indefensión de derechos que se encuentran actualmente los trabajadores para hacer cumplir sus derechos a cobertura por riesgo y enfermedad laboral, y los respectivos servicios de prevención de accidentes".

Las condiciones descrita, determinan que los accidente laborares son representativas para el fracaso financiero de las industria en especial para la del sector de la construcción a más de constituir una afectación social para el país.

Se considera el interés en el tema de costes de los accidentes laborales en el sector de la construcción, por la importancia que los empresarios y gerentes que lideran la industria de la construcción conozca bien en términos económicos lo que representa un accidentes, siendo la mejor forma de llamar una verdadera atención e involucramiento en la gestión de la prevención. Así 
inculcar una cultura-empresarial de prevención de manera se vea como lo que realmente es rentabilidad.

En este trabajo de investigación procurará establecer costes medios aproximados que se incurren en los accidentes laborales en el sector de la construcción en el Ecuador. Sabiendo que cada accidente laboral es diferente a otro y que los costes que interviene dependerá de la severidad del evento. 


\section{Materiales y métodos.}

El tipo de investigación está diseñado y estructurado en estudio documental y de campo bajo las actividades que a continuación analizaremos:

\section{Recolección de información}

Para el proceso de recopilación de información se desarrolló en dos sub actividades: Exploración documental digital y la recopilación de datos estadísticos en trabajo de campo.

La Exploración documental digital se basó en estudios de tesis, trabajos de investigación entre otros sobre el estado del sector de la construcción en el Ecuador, también se exploró la normativa nacional vigente sobre seguridad y salud laboral, así como la literatura más significativa que describe el marco teórico.

La recopilación de los datos estadísticos se obtuvo de información de Instituciones públicas como:

- Instituto Nacional de Estadísticas y Censo (INEC).

- Ministerio de Trabajo (MDT).

- Instituto Ecuatoriano de Seguridad Social (IESS).

También se obtuvieron datos estadísticos de accidentes laborales de varias obras de construcción en el ecuador información levantada en investigación de campo.

Análisis e interpretación de la información 
Para el desarrollo del presente trabajo se fundamenta en el análisis e interpretación de la información obtenida en la etapa anterior donde se valora la situación actual de la Seguridad y Salud Laboral en el Ecuador.

El enfoque que tiene el análisis de la información recopilada será en las consecuencias económicas que se inciden por la materialización de los accidentes laborales.

Determinación de los costes que influyen en los accidentes laborales.

Después del análisis e interpretación de la información se determinaron los tipos de costes que influyen en los accidentes laborales los cuales son dos tipos: coste asegurado y no asegurado.

Los costes asegurados, según indica (Carvajal, 2011) "estos costes proceden a las contribuciones que de carácter obligatorio el empleador debe pagar a la seguridad social con el fin de que todos los trabajadores estén cubiertos por un seguro en caso de un accidente, y también a los gastos de todas aquellas actividades y elementos que se deben tener en cuenta para la prevención y cumplir con la normativa vigente".

Los costes no asegurados, según indica (Carvajal, 2011) "son aquellos que se derivan directamente de la ocurrencia de los accidentes e implican un consumo de recursos materiales y económicos según la gravedad del accidente”.

\section{Sistematización de los tipos de costes}

Teniendo determinado los tipos de costes influyen en los accidentes laborales, diseñaremos el modelo de sistematización de cálculo económico por los riesgos más comunes en las obra de la construcción. 


\section{Resultados.}

El análisis de datos estadístico de los accidentes laborales que se han registrado en el ecuador será la fundamento para desarrollo de este trabajo de investigación y será la técnica que permitirá conocer la circunstancia de cómo se producen los accidentes, con qué frecuencia, su origen, gravedad, en que área de trabajo existe el riesgo crítico y parte del cuerpo más expuestas entre otras.

Entre los datos estadísticos analizados tenemos:

- Población económicamente activa y ocupada por sector económico.

- Accidentes laborales reportados.

- Distribución de los accidentes laboral a nivel nacional

- Accidentes por sector económico.

- Accidentes según gravedad.

- Partes de cuerpo lesionado

\section{Población Económicamente activa}

A continuación se presenta la evolución de la población económicamente activa en el Ecuador, la Organización Internacional del Trabajo (OIT) define qué: "La población económicamente activa incluye a todas las personas de ambos sexos que constituyen la mano de obra disponible para la producción de bienes y servicios (entre 15 y 64 años).

Dentro de ella se distingue los ocupados, que son aquellos que trabajan y reciben algún tipo de pago por sus tareas, los desocupados, que son los que no tienen un empleo pero lo buscan o están a la expectativa de alguno 


\begin{tabular}{|c|c|c|c|c|}
\hline \multirow{2}{*}{ Años } & \multicolumn{4}{|c|}{ MERCADO LABORAL NACIONAL } \\
\cline { 2 - 5 } & PEA & OCUPADOS PLENOS & DESEMPLEADOS & SUBEMPLEADOS \\
\hline 2001 & 6.563 .224 & 2.421 .017 & 555.937 & 3.586 .270 \\
\hline 2003 & 6.070 .345 & 2.085 .225 & 566.476 & 3.418 .644 \\
\hline 2004 & 6.545 .188 & 2.589 .582 & 435.495 & 3.520 .112 \\
\hline 2005 & 6.486 .112 & 1.936 .947 & 434.177 & 4.114 .988 \\
\hline 2006 & 6.772 .557 & 1.976 .786 & 429.714 & 4.366 .057 \\
\hline $2007^{*}$ & 6.548 .109 & 2.239 .662 & 327.409 & 3.915 .533 \\
\hline $2008^{*}$ & 6.536 .310 & 2.338 .642 & 385.777 & 3.796 .410 \\
\hline $2009^{*}$ & 6.685 .111 & 2.107 .804 & 432.171 & 4.015 .804 \\
\hline $2010^{*}$ & 6.535 .240 & 2.440 .268 & 326.199 & 3.714 .379 \\
\hline $2011^{*}$ & 6.647 .203 & 2.695 .299 & 278.761 & 3.633 .692 \\
\hline
\end{tabular}

Tabla $\mathbf{n}^{\circ} 1$

Evolución de la población económicamente activa Fuente: Encuesta Nacional de Empleo, Desempleo y Subempleo - ENEMDU

La población activa se puede clasificar teniendo en cuenta varios criterios, como: la rama o sector de actividad, la ocupación, la situación profesional, etc. El criterio más utilizado y simple, también como indicador del desarrollo de una determinada sociedad, es el que tiene en cuenta el sector de la economía en el que la población activa realiza sus actividades: primarias, secundarías y terciarias. El sector primario, cuya actividad principal es la agricultura, en los países desarrollados los porcentajes de población ocupada en este sector son extremadamente reducidos, se trata de una agricultura tecnificada e industrializada. La mayoría de la población ocupada en este sector es de los países con escaso desarrollo económico. El sector secundario, representado por la actividad industrial, presenta una situación opuesta a la del sector primario. En términos generales, los países desarrollados cuentan con los porcentajes más elevados (superiores al 30\%) y los países en desarrollo valores que se encuentran entre el $10 \%$ y el $20 \%$. 
El sector terciario, orientado a las actividades comerciales y a los servicios (los que son públicos como la educación y la salud, los profesionales, los transportes, etcétera), ha sufrido un acelerado crecimiento en los últimos años. En los países desarrollados, esta expansión se debe a una mayor demanda de servicios más especializados (en el campo del comercio, el transporte, la recreación, la información, etc.). En el gráfico No 1 se ilustra la evolución del personal ocupado por ramas de actividades en base a datos de la Encuesta Nacional de Empleo, Desempleo y Subempleo ENEMDU (Ver anexo No.1) encasillados en grupos de sector económico: primarios, secundarios y terciario".

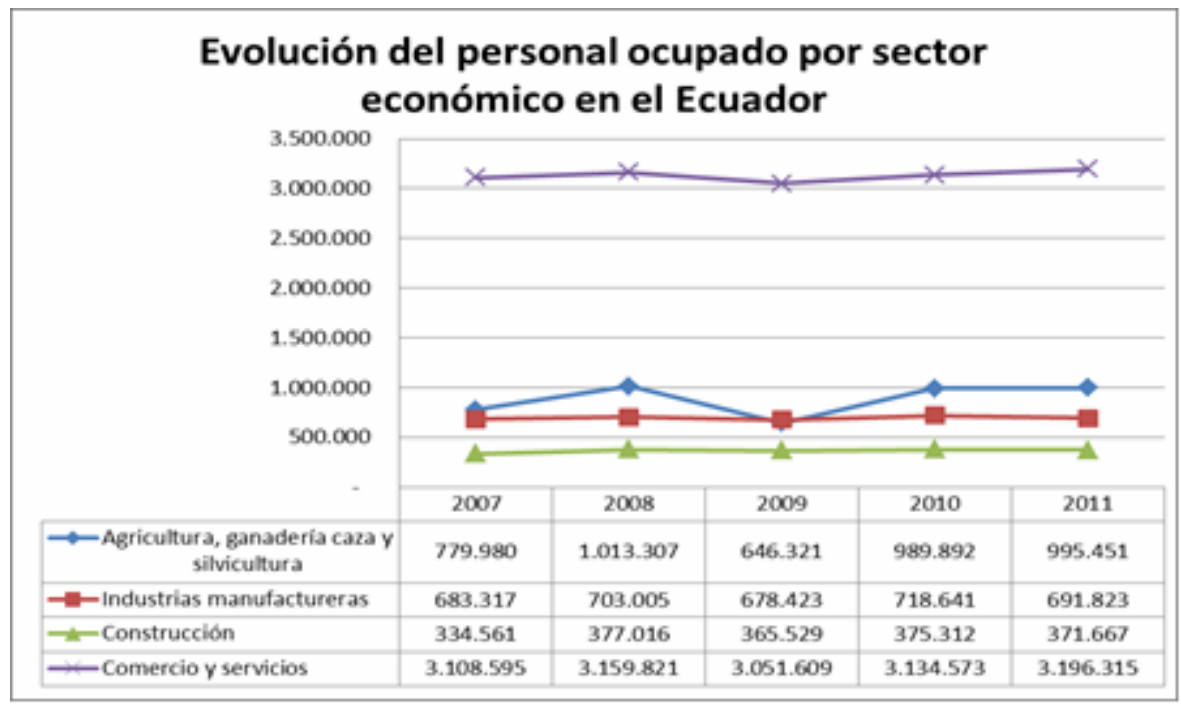

\section{Gráfico n ${ }^{\circ} 1$}

Evolución del personal ocupado por sector económico entre 2007 y 2011 Fuente: Encuesta Nacional de Empleo, Desempleo y Subempleo - ENEMDU

En cuanto a los sectores económicos, podemos observar que el sector comercial-servicio es el que presenta un mayor incremento de personal ocupado entre 2007-2011, y los demás sectores económico, siguiendo una tendencia similar a la del total de ocupados, vemos que los sectores de la 
construcción, industria y servicios siguen una tendencia lineal en cuanto a personal ocupado en el mismo período.

Población ocupada en el sector de la construcción

Durante 2011 la media anual de población ocupada en el sector de la construcción fue 371.667 trabajadores, lo que significa el $7.03 \%$ de la población ocupada total del Ecuador en ese año. La media anual de la población ocupada en construcción entre 2007 y 2011 muestra una evolución estable o con poca variación así tenemos que el porcentaje de captación pasa de 7.49 al 7.03 .

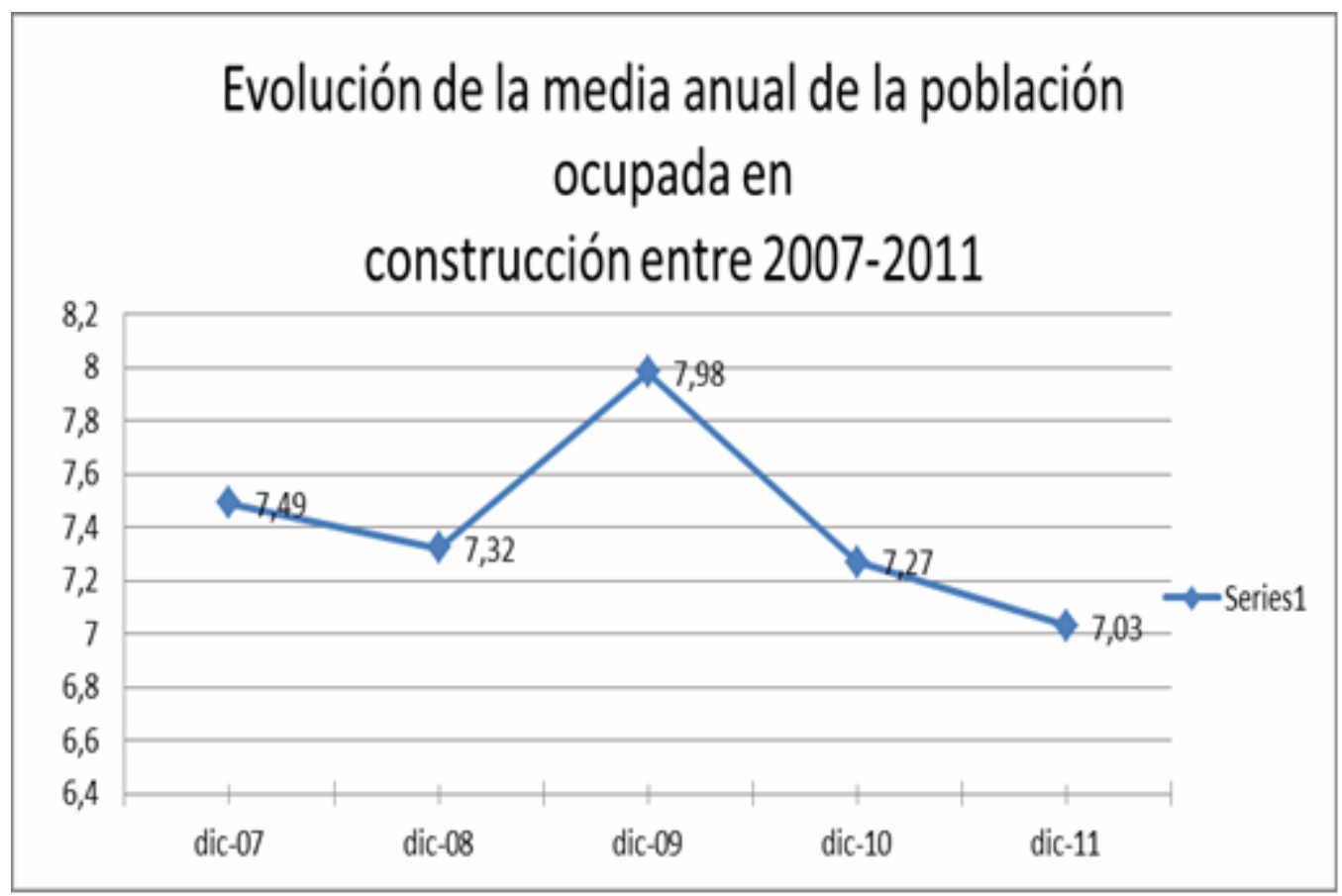

Gráfico n $^{\circ} 2$

Evolución del personal ocupado en el sector de la construcción entre 2007 y 2011

Estadísticas de accidentes laborales

Las estadísticas de accidentes de trabajo disponible en el Ecuador son la que registra el Instituto Ecuatoriano de Seguridad Social a través de la Dirección Nacional del Seguro General de 
Riesgos del Trabajo, datos registrados en diferentes sectores económicos según la población afiliada al sistema de aseguramiento público, registros que ofrece limitaciones estadísticas, lo cual determina que el sub-registro de accidentes de trabajo sea importante.

En Informe de (Vélez Andrade, 2011) “En el 2011 a nivel nacional, en el Ecuador se reportaron 15.472 siniestros laborales de los cuales $15.223(98,39 \%)$ corresponden a avisos de accidentes laborales y $249(1,61 \%)$ a avisos de enfermedades profesionales”.

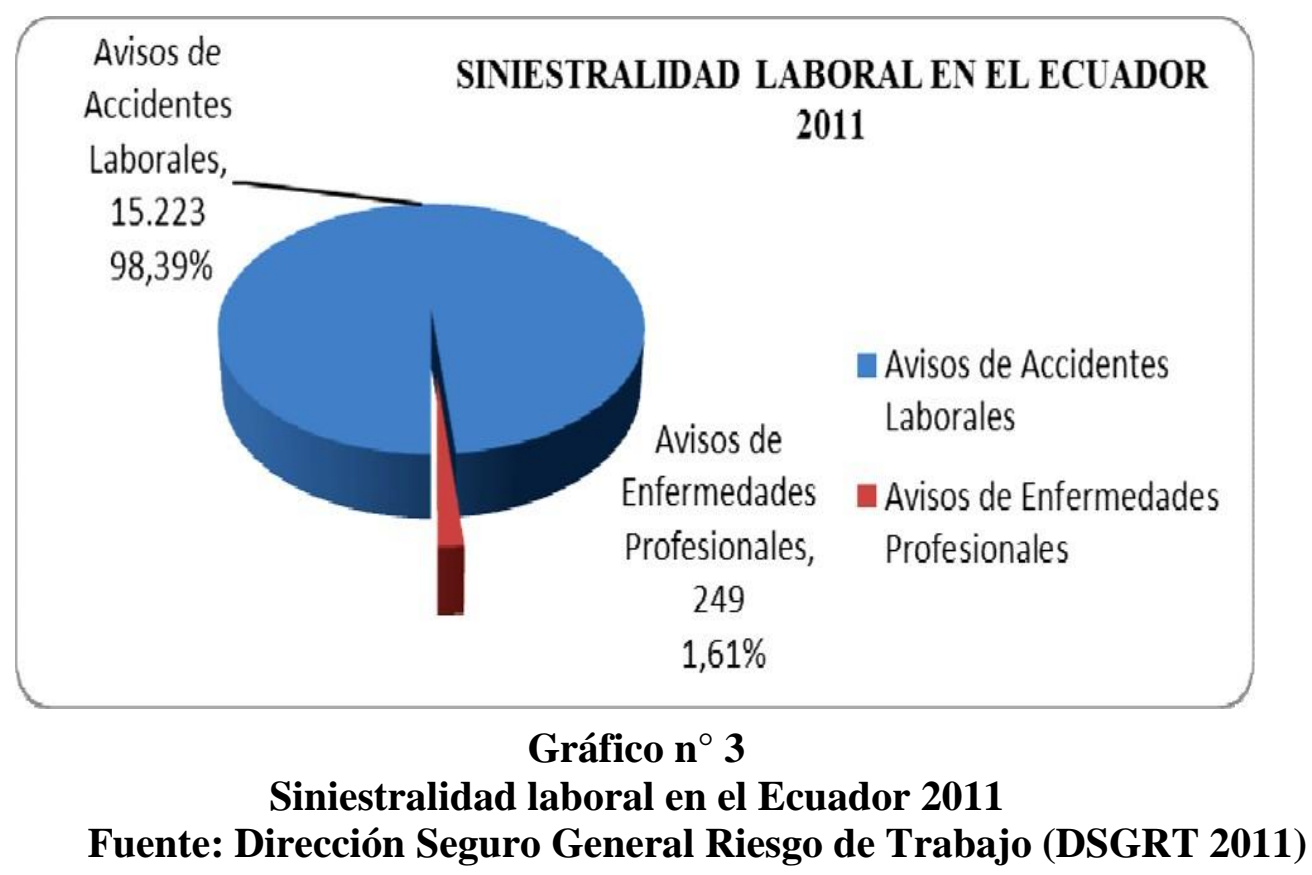

Siniestralidad Laboral en relación a años anteriores

Durante el período comprendido entre 2000 y 2011, la accidentalidad laboral pasó de 2.225 a 15.472 accidentes de trabajo (Tabla No.2.), lo que supone un incremento de 13.247 accidentes en el conjunto del período, es decir, del 248,94\%. 
Miguel A. Ordoñez-Torres; Edin A. Garcés-Coca; Héctor D. Martínez-Villacrés

\begin{tabular}{|c|r|c|}
\hline Año & No. Accidentes & $\begin{array}{c}\text { \% incremento } \\
\text { respecto al año } \\
\text { anterior }\end{array}$ \\
\hline 2000 & 2.225 & \\
\hline 2001 & 2.309 & 3,78 \\
\hline 2002 & 2.407 & 4,24 \\
\hline 2003 & 2.301 & $-4,40$ \\
\hline 2004 & 2.911 & 26,51 \\
\hline 2005 & 4.406 & 51,36 \\
\hline 2006 & 5.495 & 24,72 \\
\hline 2007 & 6.304 & 14,72 \\
\hline 2008 & 8.028 & 27,35 \\
\hline 2009 & 5.693 & $-29,09$ \\
\hline 2010 & 7.905 & 38,85 \\
\hline 2011 & 9.305 & 17,71 \\
\hline Total & 59.289 & $\mathbf{1 7 5 , 7 5}$ \\
\hline
\end{tabular}

Tabla $\mathbf{N}^{\circ} 2$

Evolución anual e incremento de

Los accidentes de Trabajo

Fuente: boletines estadísticos IESS 15, 16, 17, 18

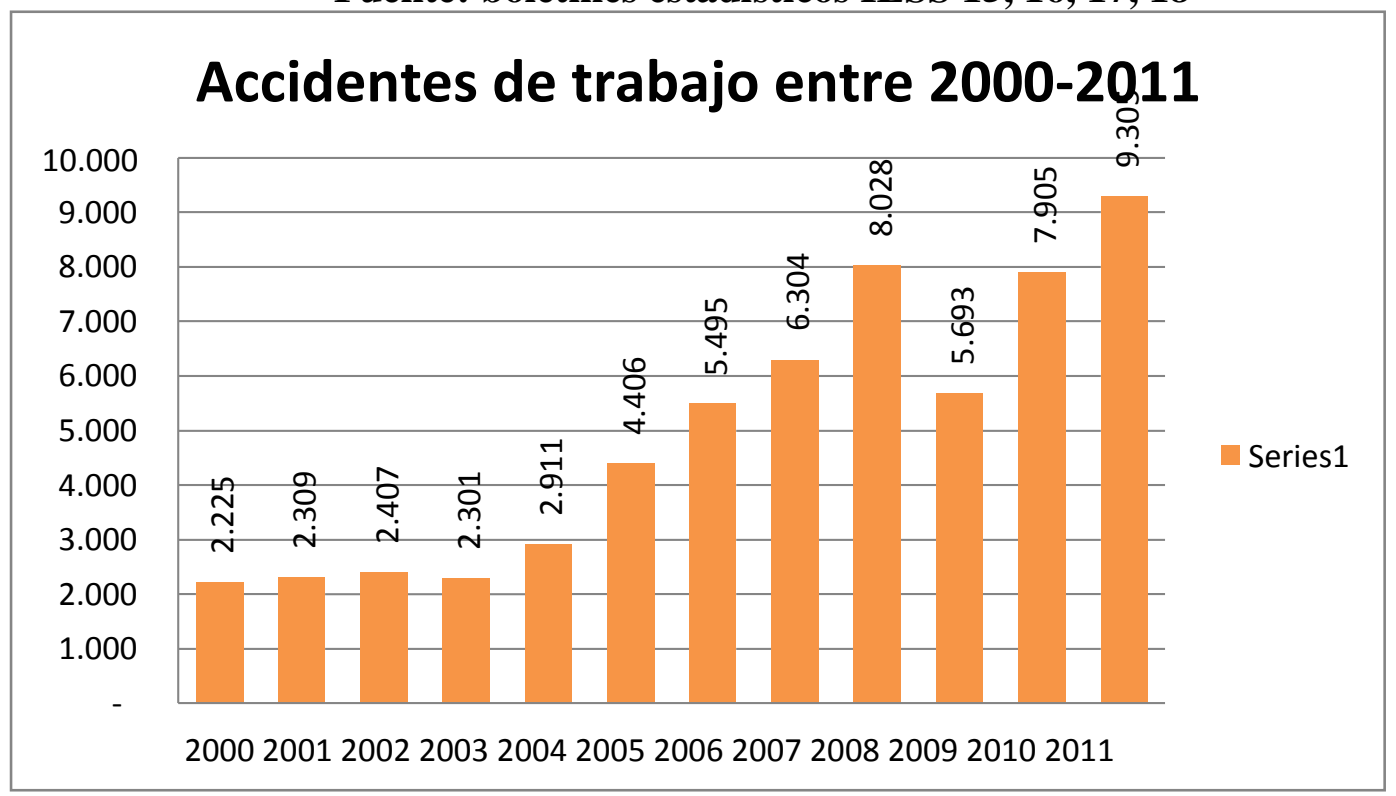

\section{Gráfico n ${ }^{\circ}$}

Accidentes de Trabajo en el Ecuador entre 2000-2011

Fuente: Encuesta Nacional de Empleo, Desempleo y Subempleo - ENEMDU

(Vélez Andrade, 2011) indica que: "Las acciones realizadas por el Seguro General de

Riesgos del Trabajo para concienciar a las empresas de los beneficios que representa el aviso oportuno de los siniestros laborales, ha generado un crecimiento en la presentación de avisos de 
accidentes de trabajo y enfermedades profesionales, de esta manera se obtendrá datos más confiables y reales de la siniestralidad laboral en el Ecuador”.

\section{Distribución de la Siniestralidad Laboral a nivel nacional}

Teniendo en cuenta los totales de accidentes de trabajo calificados entre 2005 y 2011, y haciendo la distribución de los mismos por provincia (Tabla No. 3), encontramos que el 82,99\% de estos accidentes ocurrieron en las provincias del Guayas, Pichincha y Azuay.

\begin{tabular}{|c|c|c|c|c|c|c|c|c|c|}
\hline PROVINCIA & 2005 & 2006 & 2007 & 2008 & 2009 & 2010 & 2011 & $\begin{array}{l}\text { Total por } \\
\text { provincia }\end{array}$ & $\%$ \\
\hline Azuay & 442 & 479 & 509 & 603 & 487 & 525 & 437 & 3.482 & $7,39 \%$ \\
\hline Chimborazo & 6 & 29 & 43 & 85 & 34 & 124 & 158 & 479 & $1,02 \%$ \\
\hline Cotopaxi & 115 & 74 & 146 & 151 & 116 & 276 & 316 & 1.194 & $2,53 \%$ \\
\hline El Oro & 58 & 85 & 96 & 100 & 80 & 164 & 214 & 797 & $1,69 \%$ \\
\hline Guayas & 2.984 & 3.872 & 4.445 & 5.438 & 3.929 & 3.371 & 4.181 & 28.220 & $59,85 \%$ \\
\hline Imbabura & 32 & 24 & 51 & 52 & 37 & 61 & 66 & 323 & $0,69 \%$ \\
\hline Manabí & 117 & 186 & 147 & 180 & 151 & 221 & 279 & 1.281 & $2,72 \%$ \\
\hline Pichincha & 589 & 621 & 757 & 1.245 & 738 & 1.471 & 2.005 & 7.426 & $15,75 \%$ \\
\hline Loja & & 52 & 59 & 40 & 46 & & 75 & 272 & $0,58 \%$ \\
\hline Tungurahua & 63 & 73 & 51 & 105 & 67 & 179 & 222 & 760 & $1,61 \%$ \\
\hline Bolívar & & & & 13 & 8 & 21 & 25 & 67 & $0,14 \%$ \\
\hline Loja & & & & & & 69 & 85 & 154 & $0,33 \%$ \\
\hline Los Ríos & & & & & & 725 & 409 & 1.134 & $2,41 \%$ \\
\hline Sto. Domingo & & & & & & 147 & 176 & 323 & $0,69 \%$ \\
\hline Orellana & & & & 13 & & 31 & 35 & 79 & $0,17 \%$ \\
\hline Galápagos & & & & & & 6 & 10 & 16 & $0,03 \%$ \\
\hline \begin{tabular}{|l|} 
Pastaza \\
\end{tabular} & & & & & & 19 & 22 & 41 & $0,09 \%$ \\
\hline Sucumbíos & & & & & & 42 & 49 & 91 & $0,19 \%$ \\
\hline Napo & & & & & & 20 & 24 & 44 & $0,09 \%$ \\
\hline Morona & & & & 3 & & 25 & 33 & 61 & $0,13 \%$ \\
\hline Carchi & & & & & & 17 & 23 & 40 & $0,08 \%$ \\
\hline Cañar & & & & & & 375 & 441 & 816 & $1,73 \%$ \\
\hline Zamora & & & & & 12 & 16 & 20 & 48 & $0,10 \%$ \\
\hline Total & 4.406 & 5.495 & 6.304 & 8.028 & 5.705 & 7.905 & 9.305 & 47.148 & $100 \%$ \\
\hline
\end{tabular}

Tabla $\mathbf{n}^{\circ} 3$

Total de accidentes por Provincia entre 2005-2011

Fuente: Boletines Estadísticos IESS 15, 16, 17, 18

La situación que denota que las provincias del Guayas, Pichincha y el Azuay registren mayor porcentaje de accidentes se debe a los mayores volúmenes de empleo que generan estas provincias en diversas actividades económicas por ser polos principales de desarrollo económico. 
Al hacer la distribución de accidentes por provincia (Gráfico No. 5), encontramos que la provincia del Guayas es la que registra el mayor número de accidentes laborales, del orden de los 28.220 accidentes $(59,85 \%)$ del total, seguida en orden decreciente por la provincia de Pichincha con 7.426 accidentes $(15,75 \%)$, en tercer lugar está la provincia del Azuay con 3.482 accidentes (7,39\%) y en cuarto lugar la provincia de Manabí con 1.281 accidentes (2.72\%), quedando 6.739 (14.29\%) distribuido en 20 provincias.

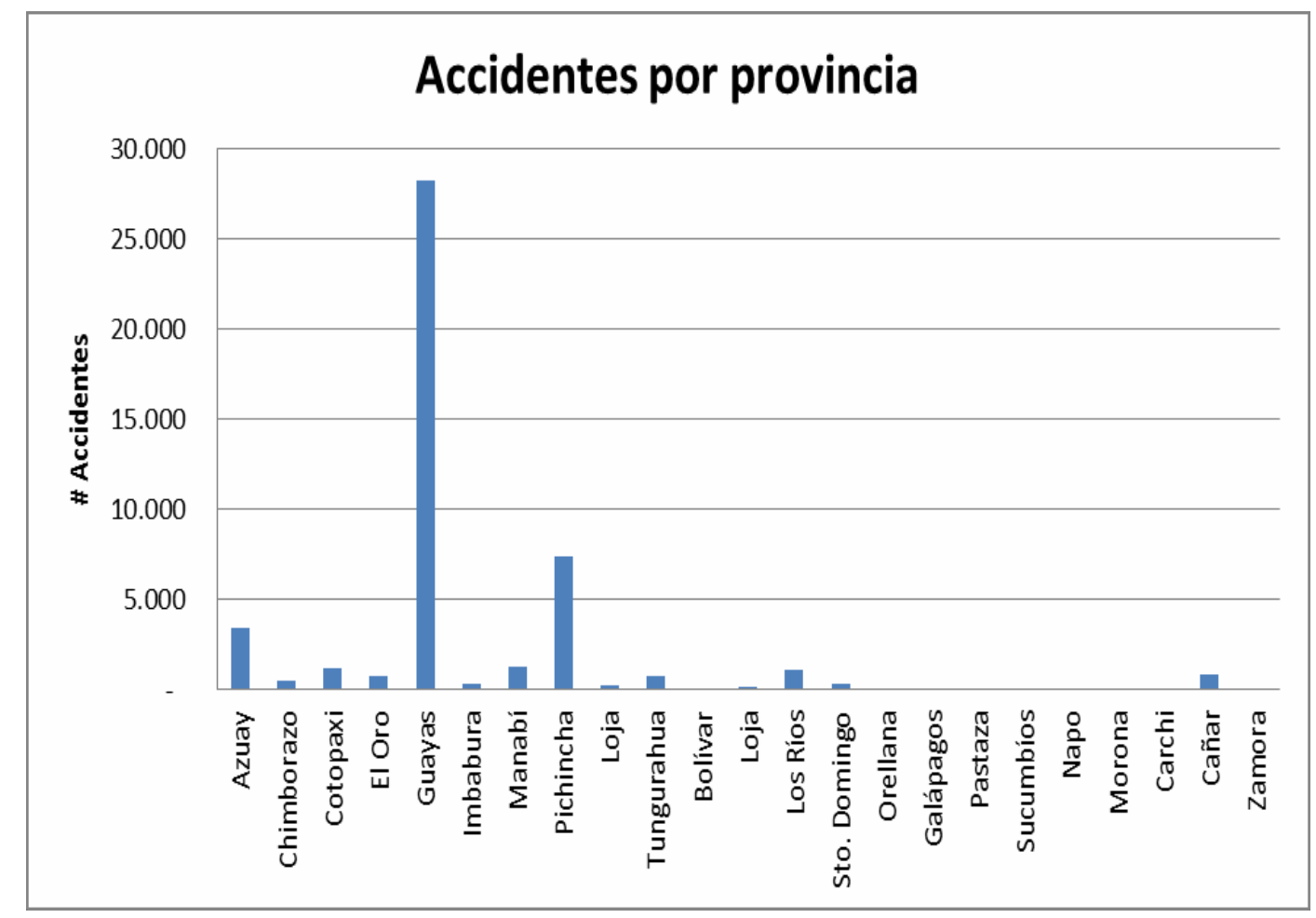

\section{Gráfico n ${ }^{\circ} 5$}

Accidentes de trabajo por Provincia entre 2005-2011

Fuente: Boletines Estadísticos IESS 15, 16, 17, 18

A continuación, en el gráfico No 6, se presenta la evolución de la siniestralidad laboral en las 3 provincias con mayor porcentaje de accidentes entre 2005-2011, Guayas, Pichincha, Azuay. 
Vemos como las 3 provincias tienen una tendencia creciente entre 2005 y 2008, con mayor pronunciamiento para la provincia del guayas, quien a partir de 2009 y hasta 2010 mantuvo una tendencia decreciente, pero que a partir de 2011 presenta un crecimiento. Pichincha similar al Guayas a partir del 2009 presenta una tendencia decreciente hasta el 2010 que presenta crecimiento durante el resto del período, la provincia del Azuay tiene un comportamiento estable durante el periodo en análisis.

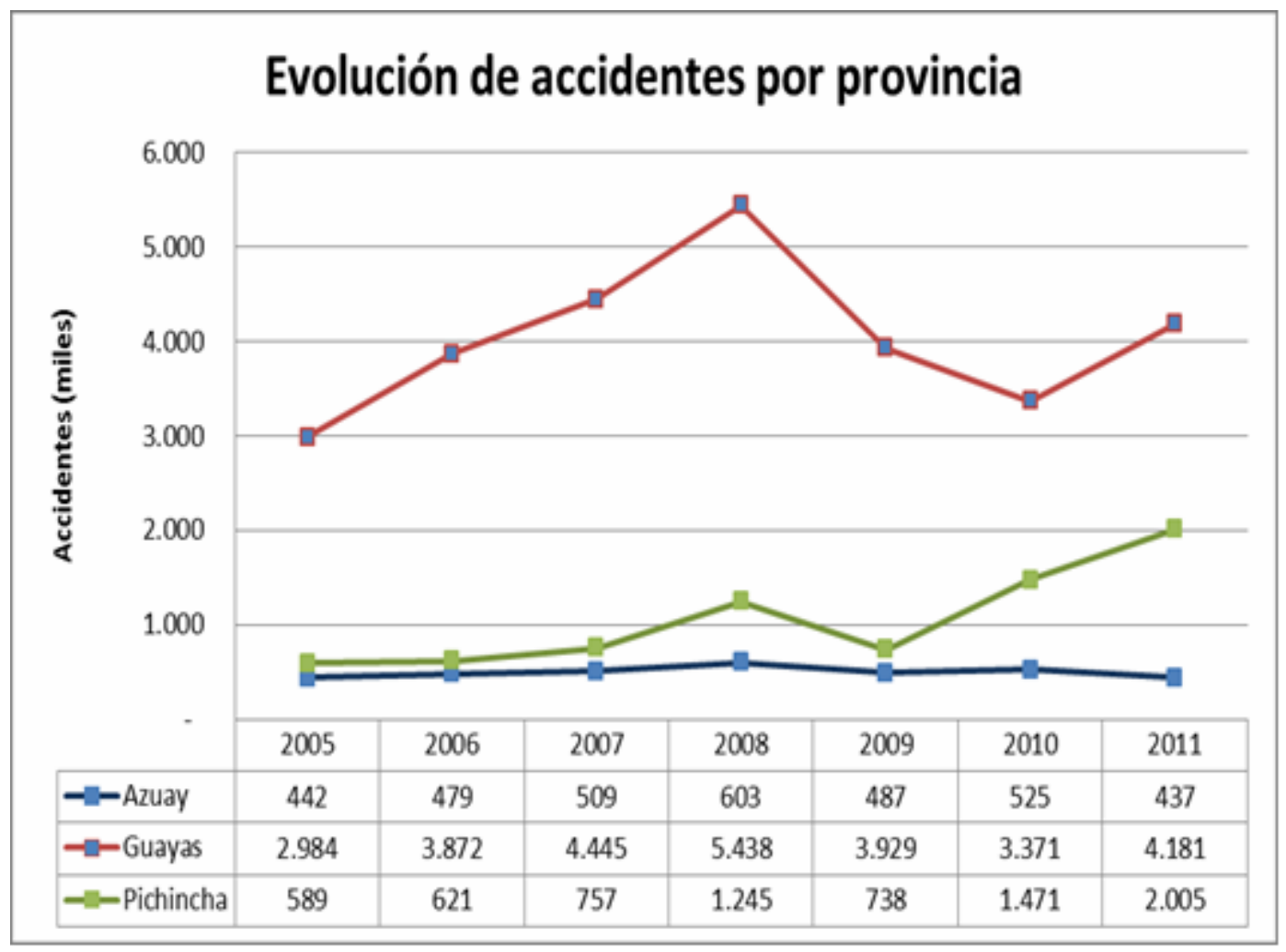

\section{Gráfico n ${ }^{\circ} 6$}

Evolución de accidentes de Trabajo por Provincia de mayores porcentajes 2005-2011 Fuente: Boletines Estadísticos IESS 15, 16, 17, 18

Accidentes de trabajo calificados por tipo de Incapacidad 
Después de haber detallado el panorama nacional de accidentes, conviene establecer un análisis según el tipo de incapacidad por sector económico. Es importante anotar que esta variable depende únicamente del dictamen médico, lo que da pie a que se presenten muchos fallos estadísticos ya que un accidente hoy puede ser considerado incapacidad temporal y días después ocasionar molestias graves o incluso la muerte; el dictamen que consideran para estos efectos es el inicial.

Para elaborar este análisis, en nuestra base de datos no se contaba con información completa sobre los tipos de incapacidad en los años 2005, 2008 y 2009, por lo cual basamos en proyecciones de promedio de porcentajes de los años 2006, 2007,2010 y 2011.

Dentro de esta clasificación y teniendo en cuenta el total de accidentes de trabajo calificados, encontramos que los de tipo incapacidad temporal representan el 89,84\% del total, las incapacidades permanentes el 6,95\%, y los mortales el 3,21\%. (Tabla No. 4).

\begin{tabular}{|c|c|c|c|c|c|c|}
\hline & $\begin{array}{l}\text { Incapacidad } \\
\text { Temporal }\end{array}$ & $\begin{array}{c}\text { Incapacidad } \\
\text { Permanente } \\
\text { Parcial }\end{array}$ & $\begin{array}{c}\text { Incapacidad } \\
\text { Permanente } \\
\text { Total }\end{array}$ & $\begin{array}{c}\text { Incapacidad } \\
\text { Permanente } \\
\text { Absoluta }\end{array}$ & Muerte & Total \\
\hline 2005 & 3.978 & 198 & 9 & 13 & 208 & 4.406 \\
\hline 2006 & 5.113 & 190 & & 31 & 161 & 5.495 \\
\hline 2007 & 5.895 & 253 & 8 & 14 & 134 & 6.304 \\
\hline 2008 & 7.227 & 528 & 22 & 24 & 227 & 8.028 \\
\hline 2009 & 5.136 & 300 & 12 & 15 & 230 & 5.693 \\
\hline 2010 & 6.723 & 862 & 31 & 16 & 273 & 7.905 \\
\hline 2011 & 8.274 & 698 & 30 & 23 & 280 & 9.305 \\
\hline Totales & 42.346 & 3.029 & 112 & 136 & 1.513 & 47.136 \\
\hline$\%$ & $89,84 \%$ & $6,43 \%$ & $0,24 \%$ & $0,29 \%$ & $3,21 \%$ & \\
\hline
\end{tabular}

A continuación en el gráfico No.7 podemos observar la tendencia de los accidentes laborales clasificados como incapacidad temporal, tuvo un comportamiento creciente entre 2005 y 2008 , 
donde pasaron de 3.978 a 7.227 accidentes; posteriormente decrece en el 2009 con 5.136 accidentes, y se vuelve a incrementar hasta el año 2011, donde terminaron siendo 8.274 accidentes laborales de tipo temporal.

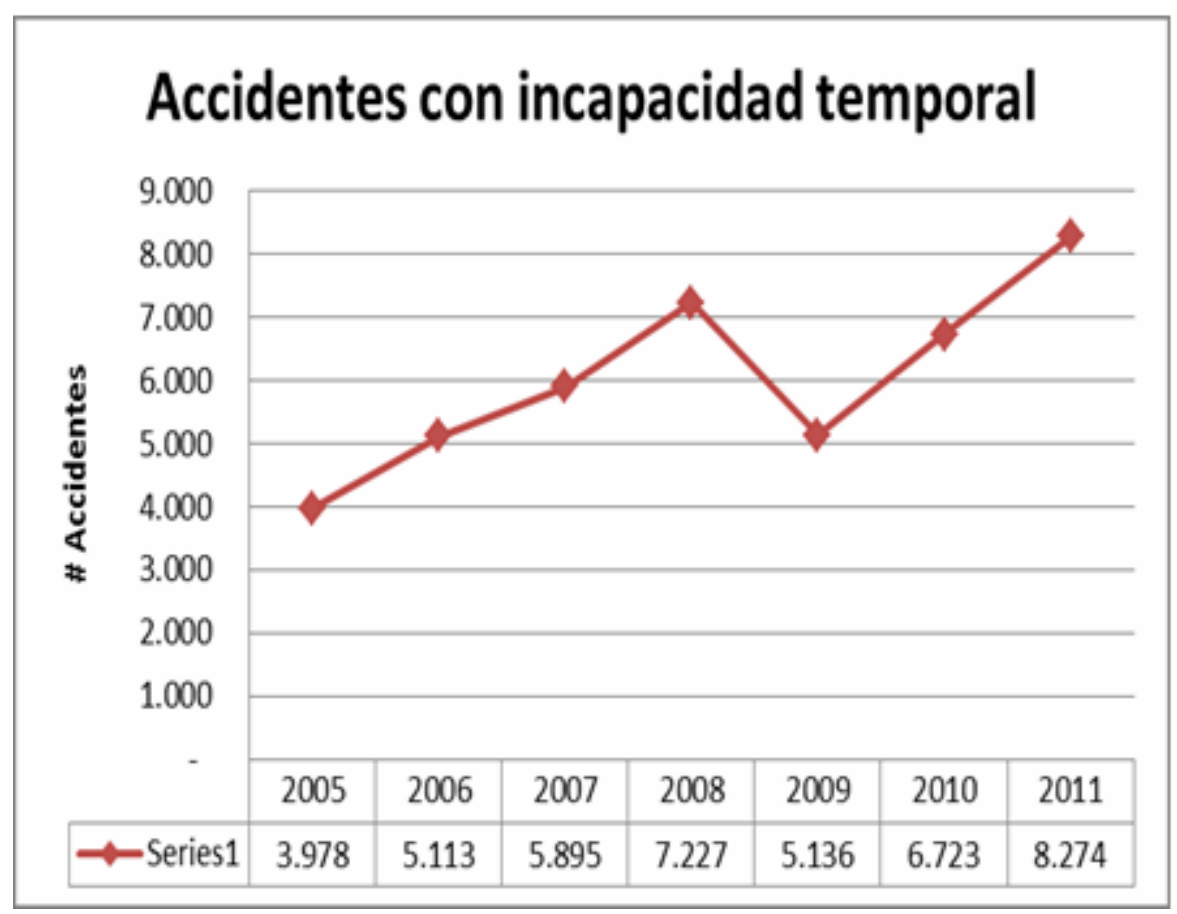

Gráfico n ${ }^{\circ}$

Evolución de accidentes de trabajo con incapacidad temporal 2005-2011

Fuente: Boletines Estadísticos IESS 15, 16, 17, 18

El balance de los accidentes con incapacidad permanente presenta una tendencia creciente lineal similar a los considerados temporales, pasando de 220 en 2005 a 574 en 2008, a partir de ahí presenta una tendencia decreciente hasta 2009, donde alcanza 327 accidentes, continúa con un acelerado crecimiento en el 2010 con 909 accidentes y a partir de allí tiene una leve reducción hasta cerrar en 2011 con 751 accidentes. (Gráfico No 8). 


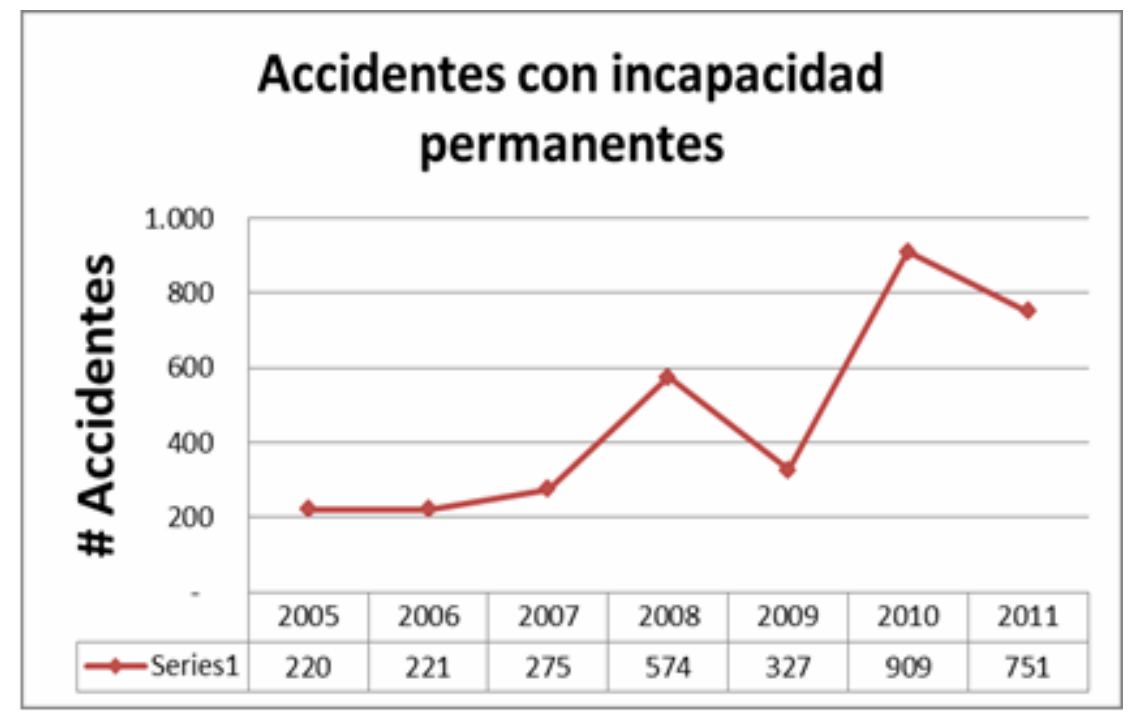

Gráfico $n^{\circ} 8$

Evolución de accidentes de trabajo con incapacidad permanente 2005-2011

Fuente: Boletines Estadísticos IESS 15, 16, 17, 18

En el caso de los accidentes mortales el comportamiento se muestra con una tendencia decreciente hasta 2007 pasando de 208 accidentes a 131, entre 2008 y 2011 la tendencia es creciente hasta llegar a 280 .

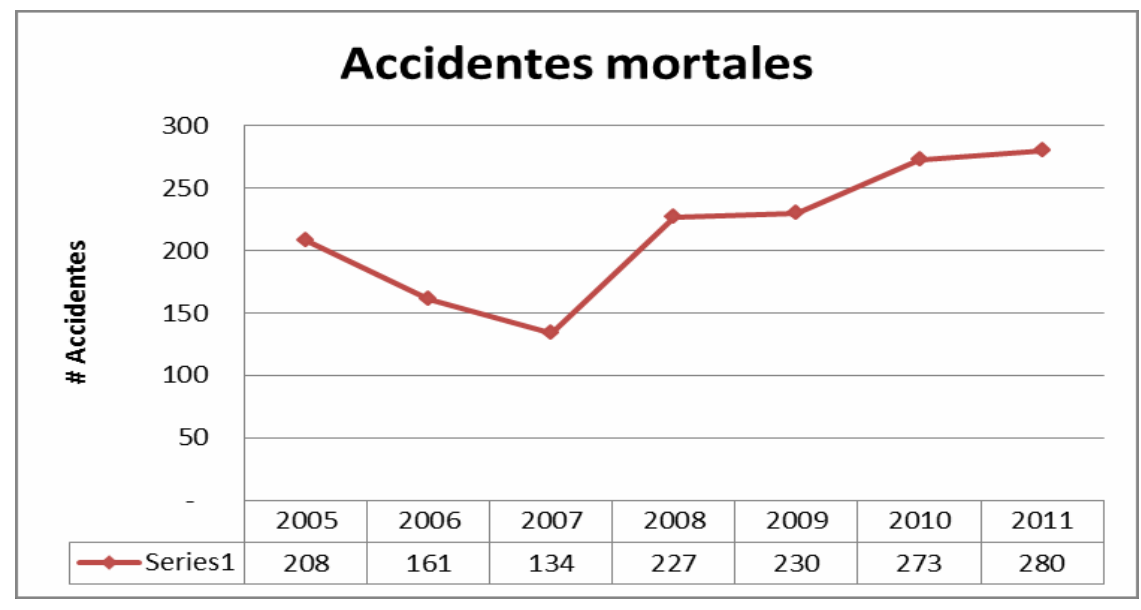

Gráfico $\mathbf{n}^{\circ} 9$

Evolución de accidentes de trabajo mortales 2005-2010

Fuente: Boletines Estadísticos IESS 15, 16, 17, 18 
Accidentes de trabajo por sector económico

Según registros del Seguro General de Riesgo del Trabajo (SGRT), durante el periodo comprendido entre 2005 y 2010, la distribución de los accidentes de trabajo por sector y rama de actividad se concentraron en el sector servicios con el 53.55\%, dentro de este sector, las ramas de comercio, transporte, financieros, y servicios sociales. Seguido el sector Industrial con 27.59\%, sector agrícola con el 11.67\%, y por último el sector de la construcción con el 7.19\% (Ver anexo No.2)

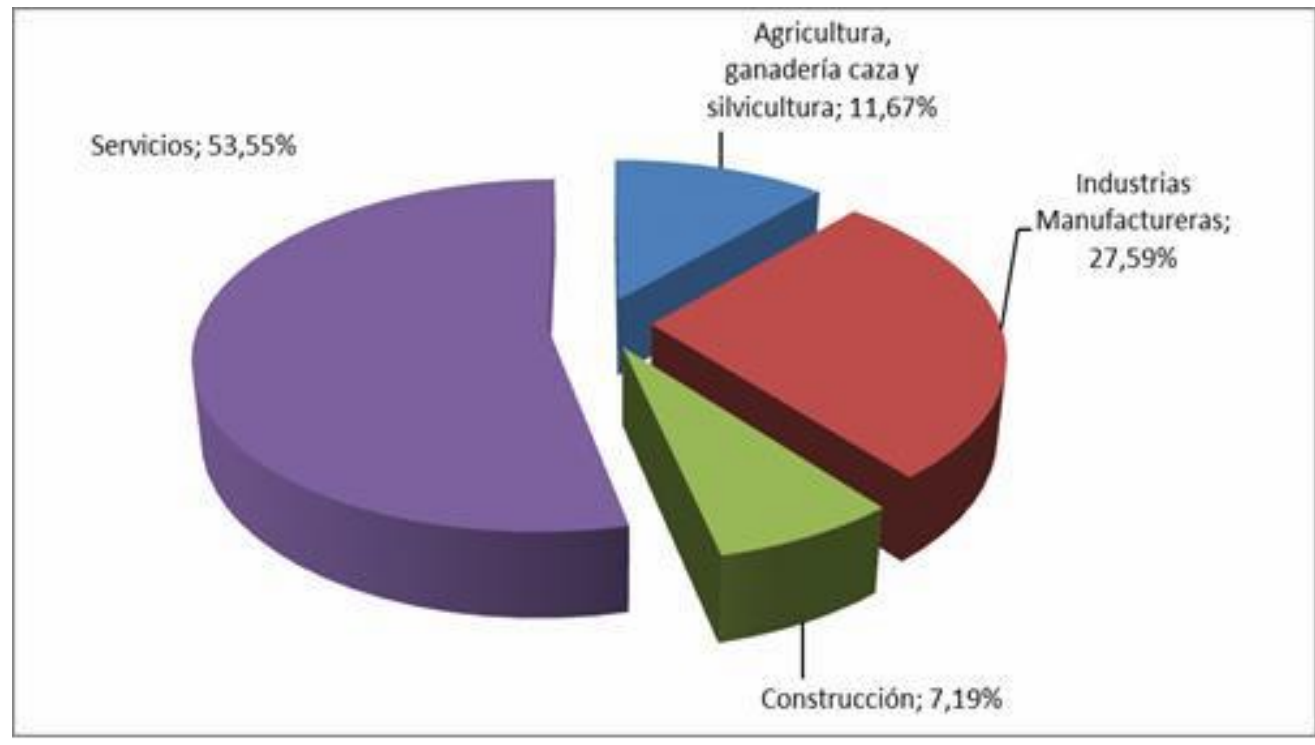

Gráfico ${ }^{\circ} 10$

Total de accidentes de trabajo por sector económico Fuente: Boletines Estadísticos IESS 15, 16, 17, 18

Como se observa en el gráfico 11, el sector con un mayor porcentaje de accidentes de trabajo es el de servicios, con 53.55\%, muy por encima del sector de la construcción $7.19 \%$, que es el que se ha caracterizado por el mayor índice de accidentes graves y mortales. 
Es importante anotar que el sector servicios, fue a los que más actividades se les atribuyeron dentro de su grupo.

Accidente de trabajo por sector económico según gravedad

Si analizamos separadamente los accidentes leves, graves, muy graves y mortales por sector económico ocurridos entre 2006-2008 y 2010, encontramos que entre el sector de servicios mantiene el mayor porcentaje accidentes en todas las categorías: leves 55\%, graves y muy graves la misma tendencia del $47 \%$, y mortales el 53\%. Seguido por el sector de la industria: leves $27 \%$, graves, muy graves la misma tendencia $31 \%$ y mortales el $16 \%$.

El sector agrícola con leves $13 \%$ y graves y muy graves y mortales con la misma tendencia del $9 \%$ y por último el sector de la construcción con accidentes leves 7\%, graves y muy graves la misma tenencia $13 \%$ y accidentes mortales $16 \%$ (Gráfico 11.1, 11.2, 11.3, 1.4).

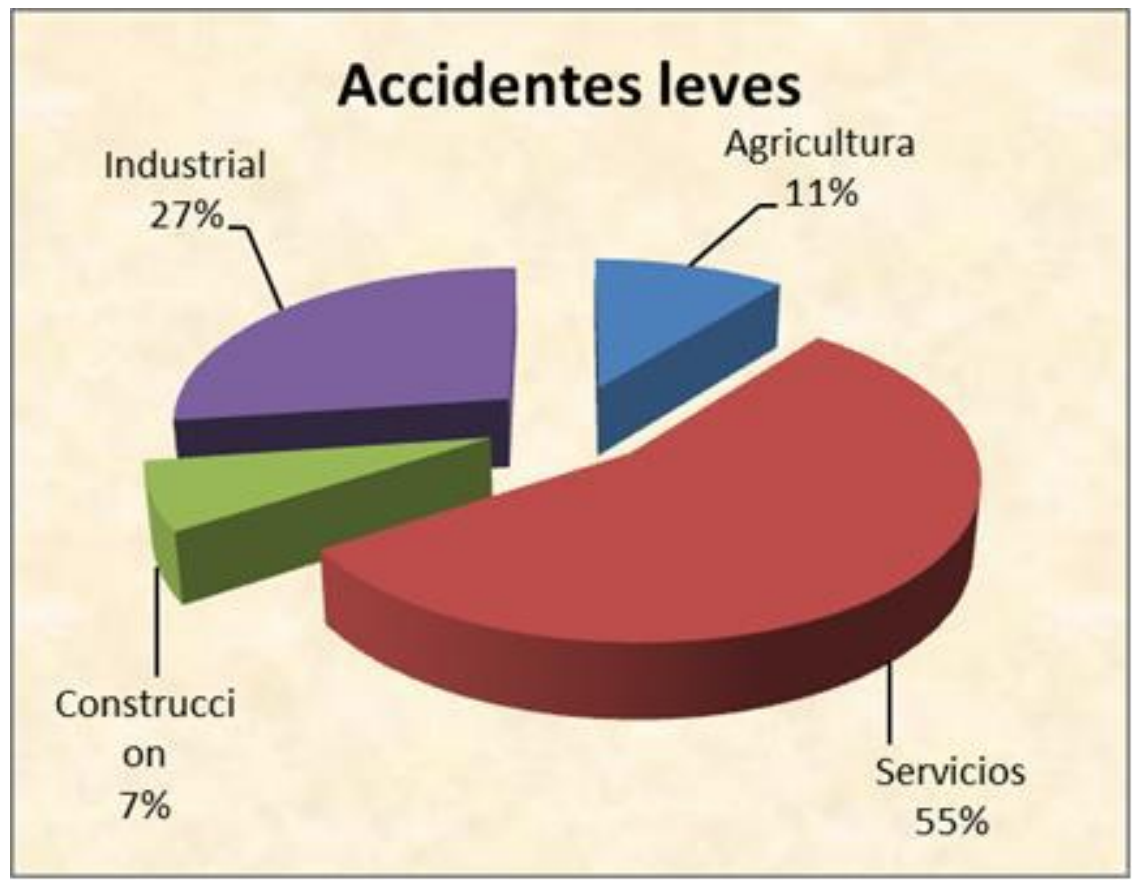

Gráfico n ${ }^{\circ} 11$

Accidentes leves por sector económico Entre 2006-2008 y 2010

Fuente: Boletines Estadísticos IESS 15, 16, 17, 18 


\section{Accidentes graves}
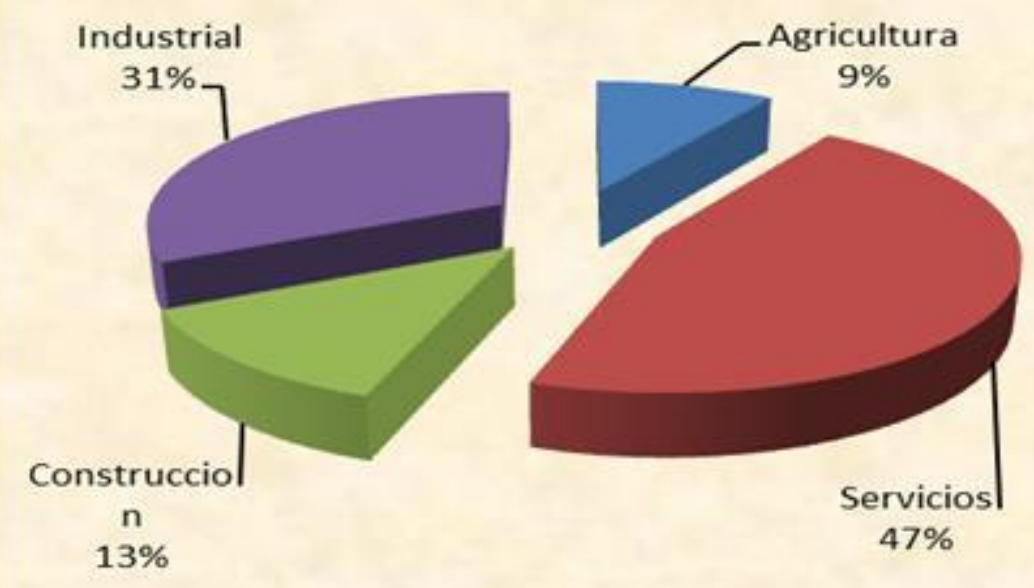

Gráfico $\mathrm{n}^{\circ} 11$ a

Accidentes graves por sector económico entre 2006-2008 y 2010

Fuente: Boletines Estadísticos IESS 15, 16, 17, 18

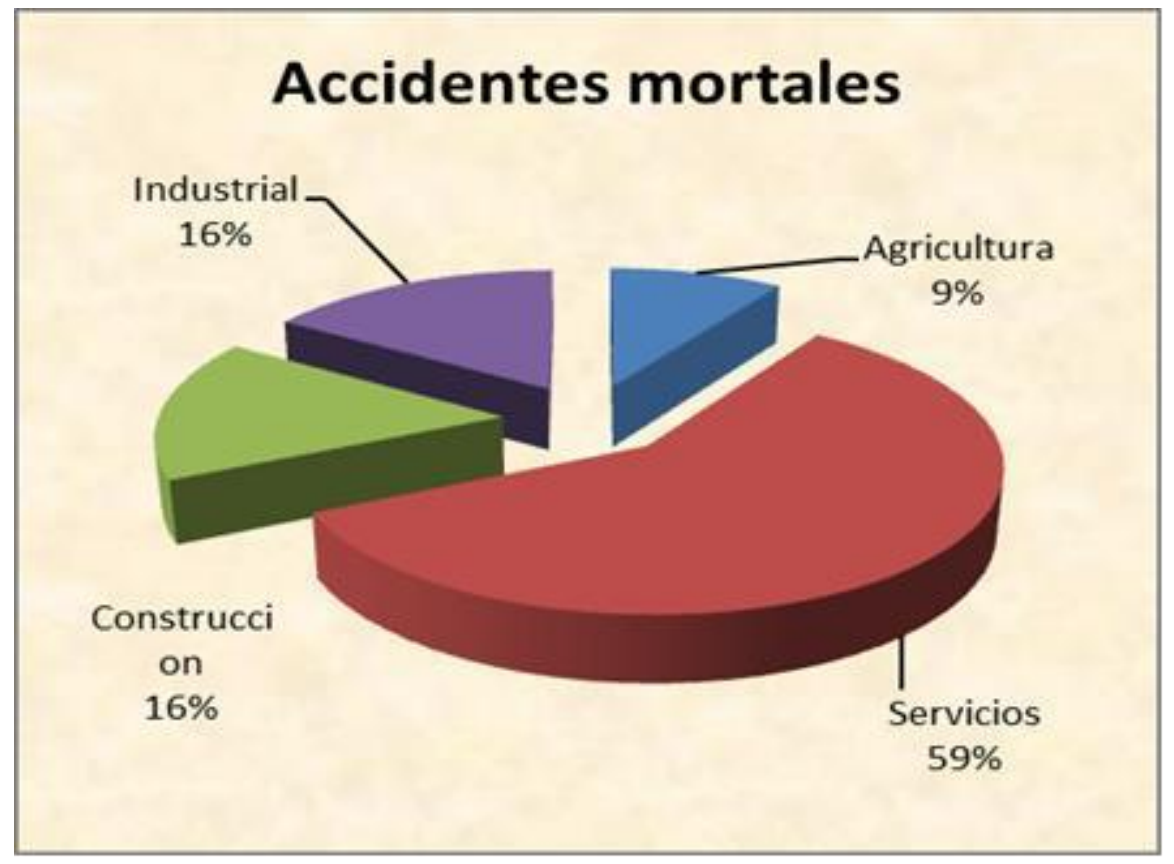

Gráfico n ${ }^{\circ} 11$ b

Accidentes mortales por sector económico entre 2006-2008 y 2010

Fuente: Boletines Estadísticos IESS 15, 16, 17, 18 


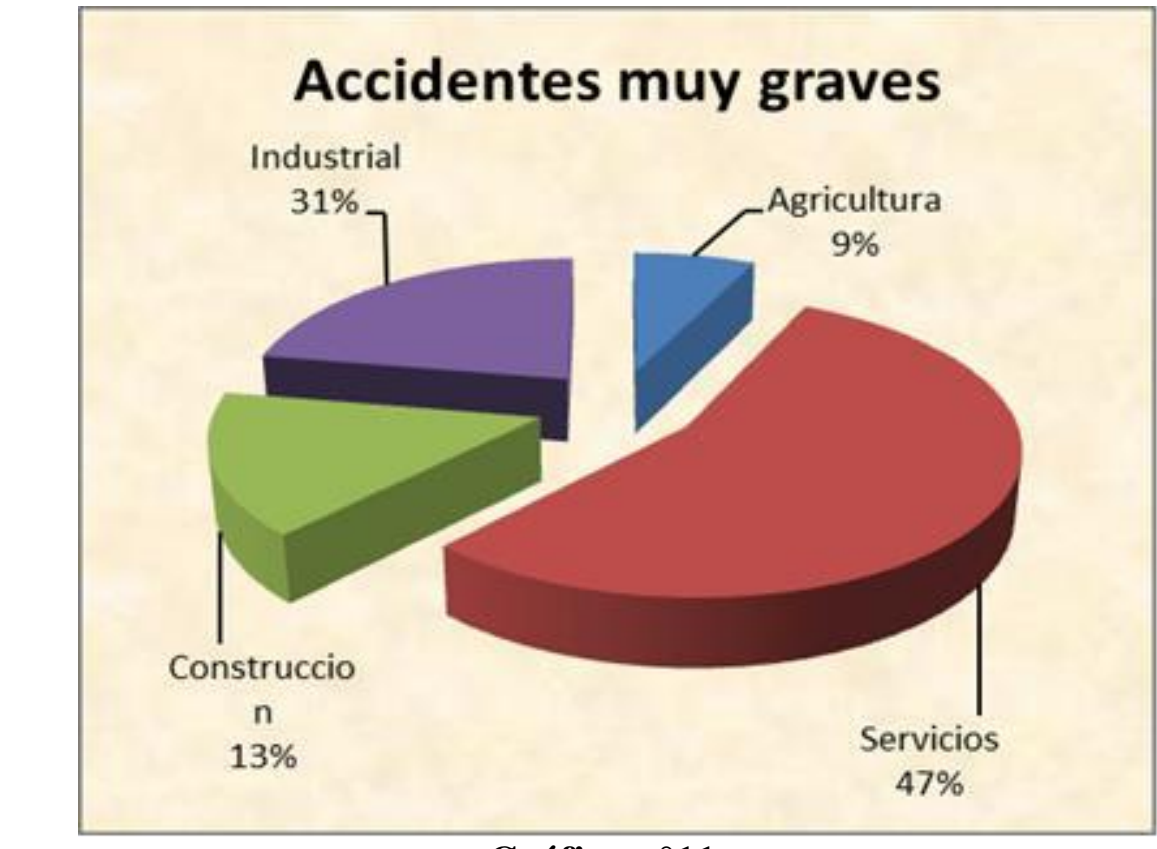

\section{Gráfico n ${ }^{\circ} 11$ c}

Accidentes muy graves por sector económico entre 2006-2008 y 2010

Fuente: Boletines Estadísticos IESS 15, 16, 17, 18

Considerando los sectores de industria, agrícola y construcción, por ser más comparables entre sí, se observa que la participación del sector de la construcción en cuanto al porcentaje de accidentes es de tendencia creciente para los leves, graves, muy graves y los mortales en el período considerado; el sector industrial y agrícola por el contrario, se mantiene y disminuye a medida que aumenta la gravedad de los accidentes.

El diferencial de 20 puntos entre industria y construcción con respecto al total de accidentes leves, se reduce a 18 puntos en los accidentes graves y muy graves, y a 0 puntos en los mortales. Ello pone de manifiesto, especialmente tratando de valores absolutos, la importancia de los riesgos y la consideración del sector de la construcción como de alto riesgo (Ver anexo No.3 Categorización del riesgo por sectores y actividades productivas por MDT). 
Un análisis efectivo de la siniestralidad laboral entre los sectores económicos debe realizarse a través de sus correspondientes índices de incidencia, ya que estos relacionan el número de accidentes ocurridos en cada sector con el número medio de personas ocupadas en el mismo, ambos considerados en el mismo período, en este caso entre 2006-2010 Por medio de este índice, encontramos el número de accidentes por cada mil trabajadores ocupados y evaluamos la peligrosidad del sector.

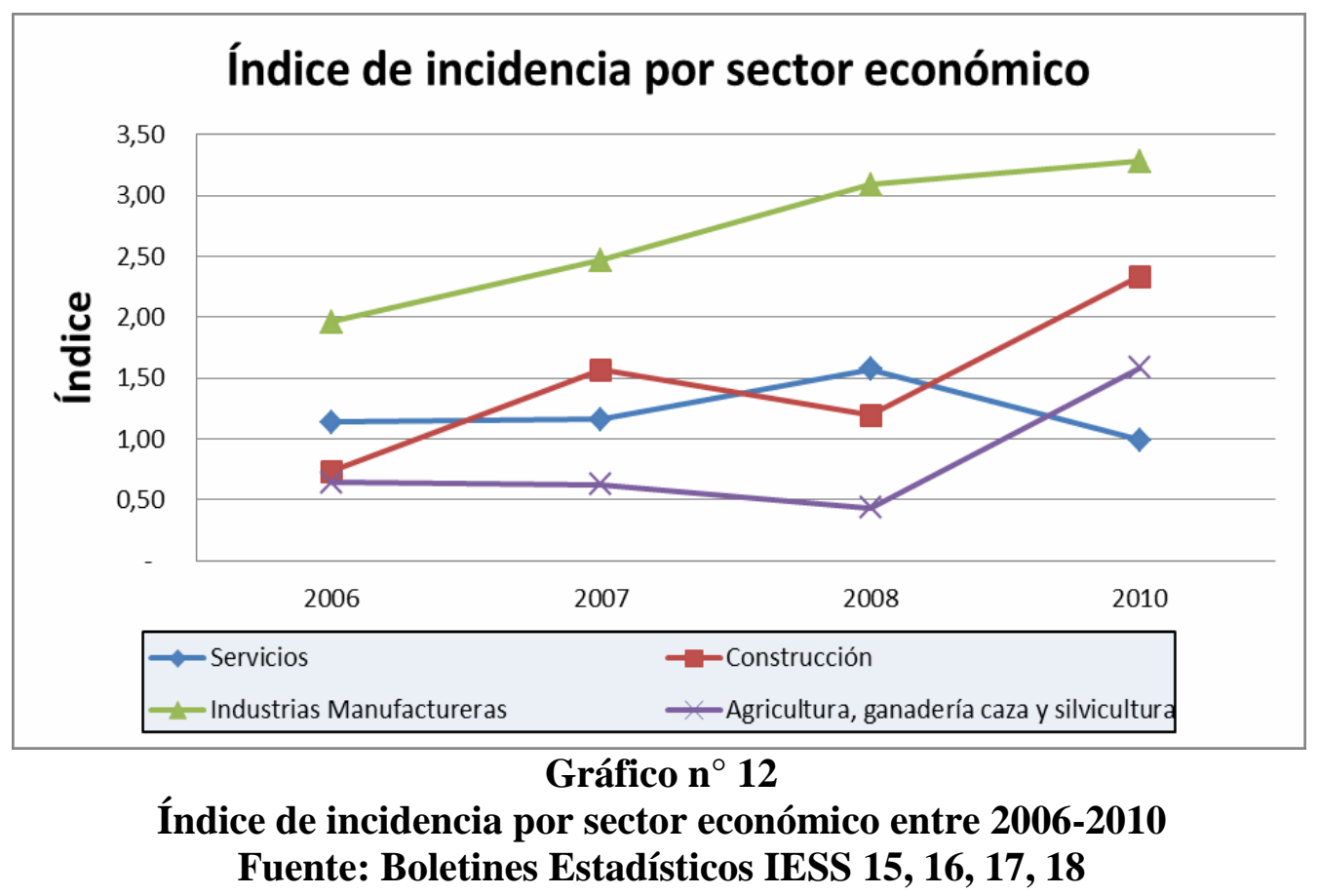

En el gráfico No. 12, podemos observar como el índice de incidencia por sectores económicos tiene una tendencia al alza en los sectores de construcción, industrial y agricultura entre el periodo 2006 y 2010, en cambio el sector de servicio la tendencia es a la baja.

Si miramos detenidamente cada sector en particular, observamos que el sector de la construcción presenta el uno de los mayores índices de incidencia, después del sector industria. 
Principales parte del cuerpo lesionada por accidentes de trabajo

Esta variable describe las zonas del cuerpo del trabajador dañadas a causa del accidente. Según Tabla No 5 y Gráfico o No 13, respectivamente, considerando el total de accidentes entre 2005-2008 y 2010 (no se cuenta con registro por parte lesionada del 2009) las partes más frecuentemente lesionadas son las extremidades superiores (28\%); seguidas de las extremidades inferiores (22\%); y de la ubicaciones múltiples (17\%), lo que supone el conjunto del 67\% de los casos.

\begin{tabular}{|c|c|c|c|c|c|c|c|c|}
\hline RAMA DE ACTIVIDAD - CIIU & Cabeza & Cuello & Tronco & \begin{tabular}{|l|} 
Miembro \\
Superior
\end{tabular} & $\begin{array}{r}\text { Miembro } \\
\text { Inferior } \\
\end{array}$ & $\begin{array}{r}\text { Ubicación } \\
\text { Múltiple } \\
\end{array}$ & $\begin{array}{l}\text { Lesiones } \\
\text { Generale } \\
\end{array}$ & TOTAL \\
\hline gricultura, Caza, Silvicultura y & 320 & 101 & 366 & 983 & 820 & 394 & 298 & 3.282 \\
\hline $\begin{array}{l}\text { Comercio por } \mathrm{M} \\
\text { Restaurantes y }\end{array}$ & 349 & 157 & 355 & 948 & 850 & 724 & 490 & 3.873 \\
\hline Construcción & 261 & 114 & 230 & 423 & 352 & 300 & 162 & 1.842 \\
\hline Electricidad, Gas y Agua & 165 & 24 & 117 & 413 & 319 & 272 & 126 & 1.436 \\
\hline $\begin{array}{l}\text { Establec, finan., seguros, bienes } \\
\text { inmuebles y servic, prestados a } \\
\text { las empresas }\end{array}$ & 356 & 233 & 456 & 1.719 & 1651 & 1243 & 953 & 6.611 \\
\hline Explotación de Minas y Canteras & 47 & 45 & 72 & 127 & 62 & 77 & 15 & 445 \\
\hline Industrias Manufactureras & 569 & 226 & 549 & 2.830 & 1405 & 1028 & 709 & 7.316 \\
\hline $\begin{array}{l}\text { Servicios Sociales, Comunales y } \\
\text { Personales }\end{array}$ & 410 & 187 & 503 & 1.280 & 1290 & 1145 & 721 & 5.536 \\
\hline $\begin{array}{l}\text { Transporte, Almacenamiento y } \\
\text { Comunicaciones }\end{array}$ & 144 & 99 & 180 & 375 & 348 & 338 & 313 & 1.797 \\
\hline TOTAL & 2.621 & 1.186 & 2.828 & 9.098 & 7.097 & 5.521 & 3.787 & 32.138 \\
\hline$\%$ & $8,16 \%$ & $3,69 \%$ & $8,80 \%$ & $28,31 \%$ & $22,08 \%$ & $17,18 \%$ & $11,78 \%$ & \\
\hline
\end{tabular}

Tabla $^{\circ} 5$

Parte del cuerpo lesionada por actividad entre 2005-2010

Fuente: Investigación de campo 


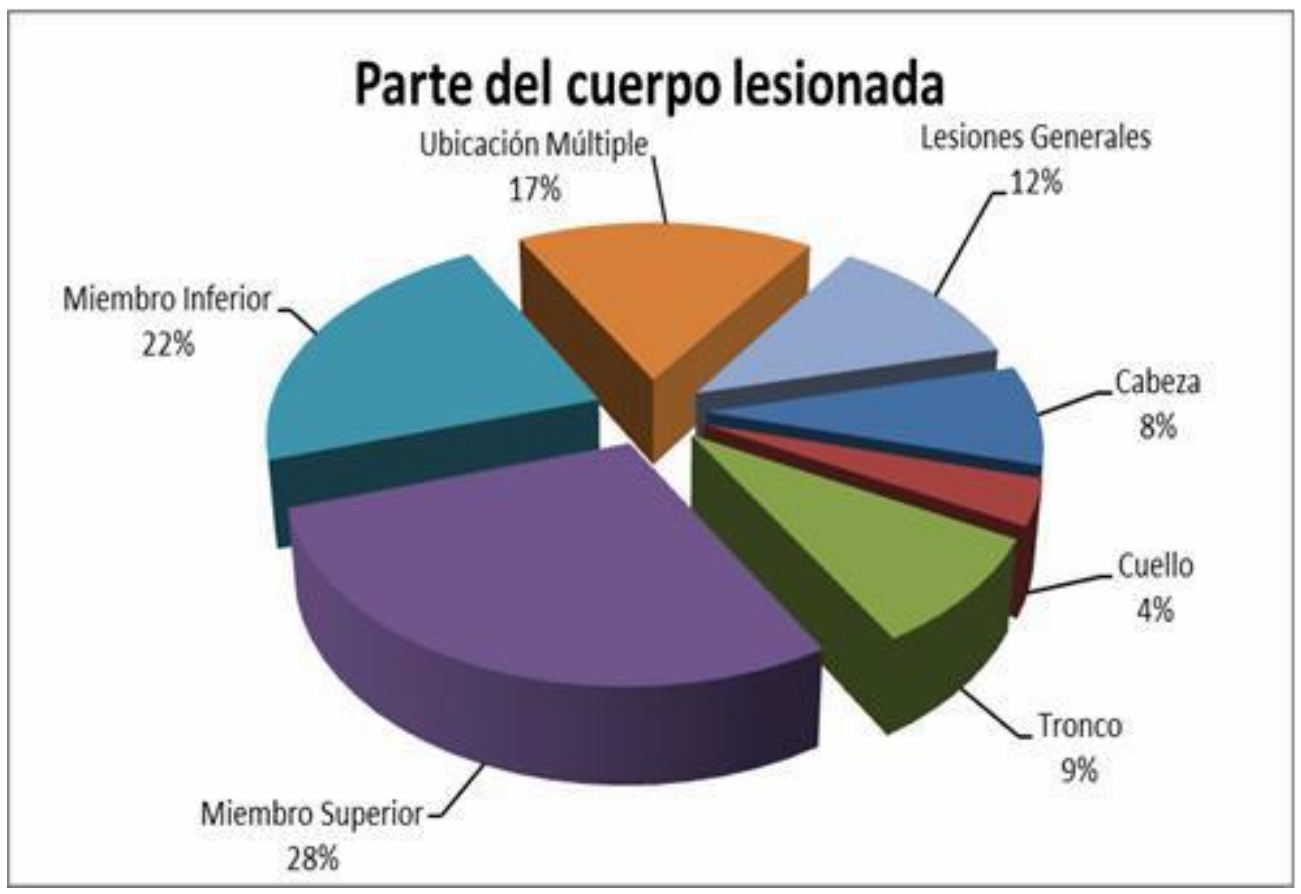

Gráfico n ${ }^{\circ} 13$

Parte del cuerpo lesionada por accidentes de trabajo entre 2005-2010

Fuente: Investigación de campo

\section{Conclusiones.}

Unos de los objetivos de este trabajo de investigación es conocer la situación actual de la Seguridad y Salud Laboral en el sector de la construcción en el Ecuador, mediante información estadística, donde se encontró las siguientes situaciones:

Escasa información estadísticas de accidentes laborales en el ecuador, manteniendo el sub registro debido al desconocimiento legal en materia de Seguridad y Salud Laboral de las empresas. 
No existe información estadística de accidentes laborales específica para el sector de la construcción, la única entidad que registra y publica accidentes de trabajo por sector empresarial es el Instituto de Seguridad Social (IESS).

El sector de la construcción contribuye al desarrollo económico del país representado un $11 \%$ al Producto Interno Bruto (PIB), y acoge el 7,30\% de la Población Económicamente Activa (PEA).

El en Ecuador los costos por accidentes laborales representa el 10\% de Producto Interno Bruto (PIB) eso quiere decir que se pierde 10 mil millones de dólares por falta de prevención.

Con la información existente en el Ecuador se puede realizar a las siguientes conclusiones:

En el periodo del 2007 al 2011 el personal ocupado en el sector de la construcción tuvo una evolución estable o con poca variación, sin embargo el índice de incidencia de accidentes en el mismo periodo tubo un atendencia a la alza pasando del índice 0,73 al 2,33, esto no significo que sucedieron más accidentes laborales, sino que existió un mayor registro de accidentes debido al incremento de afiliados a la Seguridad Social que del 2009 tenía 1.626.381 usuarios y a marzo del 2013 se tienen 2’735.996, además de entrada en vigor de nuevas normativas en materia Seguridad y Salud Laboral como de DC 333 Reglamento para el Sistema de Auditoria de Riesgo de Trabajo "SART".

La provincia del Guayas registra el mayor número de accidentes laborales del orden del 59,85\% del total, seguida en orden decreciente por la provincia de Pichincha con el $15,75 \%$, en tercer lugar está la provincia del Azuay con el 7,39\% y en cuarto lugar la provincia de Manabí con el 2.72\%, quedando $14.29 \%$ distribuido en 20 provincias. 
Las partes más frecuentemente lesionadas en los trabajadores son las extremidades superiores (28\%); seguidas de las extremidades inferiores (22\%); y de la ubicaciones múltiples (17\%), lo que supone el conjunto del $67 \%$ de los casos.

Para el diseño de la estructura del modelador de cuantificación de riesgo laboral para el sector de la construcción en el Ecuador, se efectúo revisión documental de cuatro estudios de modelos estimativos de costes de accidentes y que se vienen empleando por organismos y técnicos SSL, en el país de España. Se estableció dos grupos de costes, coste Asegurado que corresponde a los incurridos por el aseguramiento y asignación de recurso para la gestión de riesgo laborales y los costos no asegurado que corresponde a los incidido por los accidentes esperado por tipo de riesgo más comunes en el sector de la construcción.

Una vez realizado un ejemplo práctico sobre un proyecto de obra con costo aproximado 2,500.000.00, se concluye que optimo se el porcentaje de asignación de recurso para la implementación de Prevención de Riesgos Laborales, el costo no asegurado será mínimo por el acontecimiento de accidentes leves.

Si el porcentaje de asignación es regular o malo, el costo no asegurado se incrementara en el doble con relación a la inversión media prevención por los acontecimientos de accidentes graves y fatales.

Los técnicos SSL de las empresas constructoras dispondrán de una herramienta de información estimativa de costos de los accidentes, derivados de no asignación de recurso para la aplicación prevención en las obras de construcción. Logrando argumentar que las inversiones en seguridad representa beneficios a la empresa. 


\section{Agradecimientos}

A la Universidad Estatal de Guayaquil, junto con las autoridades y personal docente de la Facultad de Ingeniería Industrial por la oportunidad para realizar la presente investigación.

\section{Bibliografía.}

Alemán, F., Vera, J., \& Ordeñan, X. (2012). Análisis y Evolución de los costos de los principales insumos del sector de la construcción en el ecuador en el período 2004 - 2011. Guayaquil: Escuela Politécnica del Litoral.

Andrade Carrera, C. (2010). Gestión de Seguridad y Salud en la Construcción de Edificaciones. Quito: Escuela Politécnica Nacional

Barral, R. L. (2003). Aplicación de Modelos de Evaluación Económica de las consecuencias de los accidentes del trabajo y enfermedades profesionales dirigidos a la medición de indicadores coste/eficacia y coste/beneficio en las actuaciones preventivas en la empresa. Guayaquil: Dirección General de Trabajo y Prevención de Riesgos Laborales, Junta de Castilla y León.

Betancourt, Ó. (2008). Informe Continental sobre la Situación del Derecho a la salud en el Trabajo. Valencia: Instituto Valenciano de Seguridad y Salud en el Trabajo

Betancourt, Ó. (2010). Salud y seguridad en el trabajo en el Ecuador. Valencia: Instituto Valenciano de Seguridad y Salud en el Trabajo.

Carvajal Peláez, Gloria Isabel; Pellicer Armiñana, Eugenio (2011). Propuesta para la evaluación del impacto económico de la siniestralidad laboral en el sector de la construcción. Revista Ingenierías Universidad de Medellín

De Luis Aboitiz, R. (2004). Programa de Análisis de Costes de Accidentes de Trabajo. Barcelona: Instituto Navarro de Salud Laboral.

León Jiménez, N (2011). Diagnóstico Situacional en Seguridad y Salud en el Trabajo Ecuador. Quito: Comunidad Andina

López Valcárcel, Alberto. (2000). Panorama Internacional de la Seguridad y Salud en el Trabajo de construcción: el caso de Bolivia, Colombia, Ecuador y Perú. Obtenido de Oficina internacional del trabajo: http://white.lim.ilo.org/spanish/260ameri/publ/docutrab/dt-9/dt_129.pdf. 